\title{
Land-Based Lidar Mapping - a New Surveying Technique to Shed Light on Rapid Topographic Change
}

The rate of natural change in
such dynamic environments
as rivers and coastlines
can sometimes overwhelm
the monitoring capacity of
conventional surveying methods.
In response to this limitation,
U.S. Geological Survey (USGS)
scientists are pioneering new
applications of light detection
and ranging (lidar), a laser-
based scanning technology that
promises to greatly increase our
ability to track rapid topographic
changes and manage their
impact on affected communities.

The detailed three-dimensional characterization of site topography is critical to many geomorphologic studies. Whether it's a matter of glacial advance and retreat, coastal-seacliff landsliding, river-sandbar accretion and erosion, or the failure of civil infrastructure during disasters, understanding how these changes progress over time depends directly on detailed collection of topographic data. A new terrestrial (land based) laser system used by the U.S. Geological Survey (USGS) exploits advancements in light-detection-andranging (lidar) technology to collect an unprecedented amount of data in a very short time. For rapidly changing natural environments, such as rivers, landslides, and beaches, sites can now be efficiently surveyed repeatedly over a period of months, days, or even hours. The high resolution of lidar data, in combination with the ability to obtain multiple datasets over a short period of time, allows researchers to more fully understand the mechanics of these dynamic natural phenomena and to calibrate models for predicting future change.

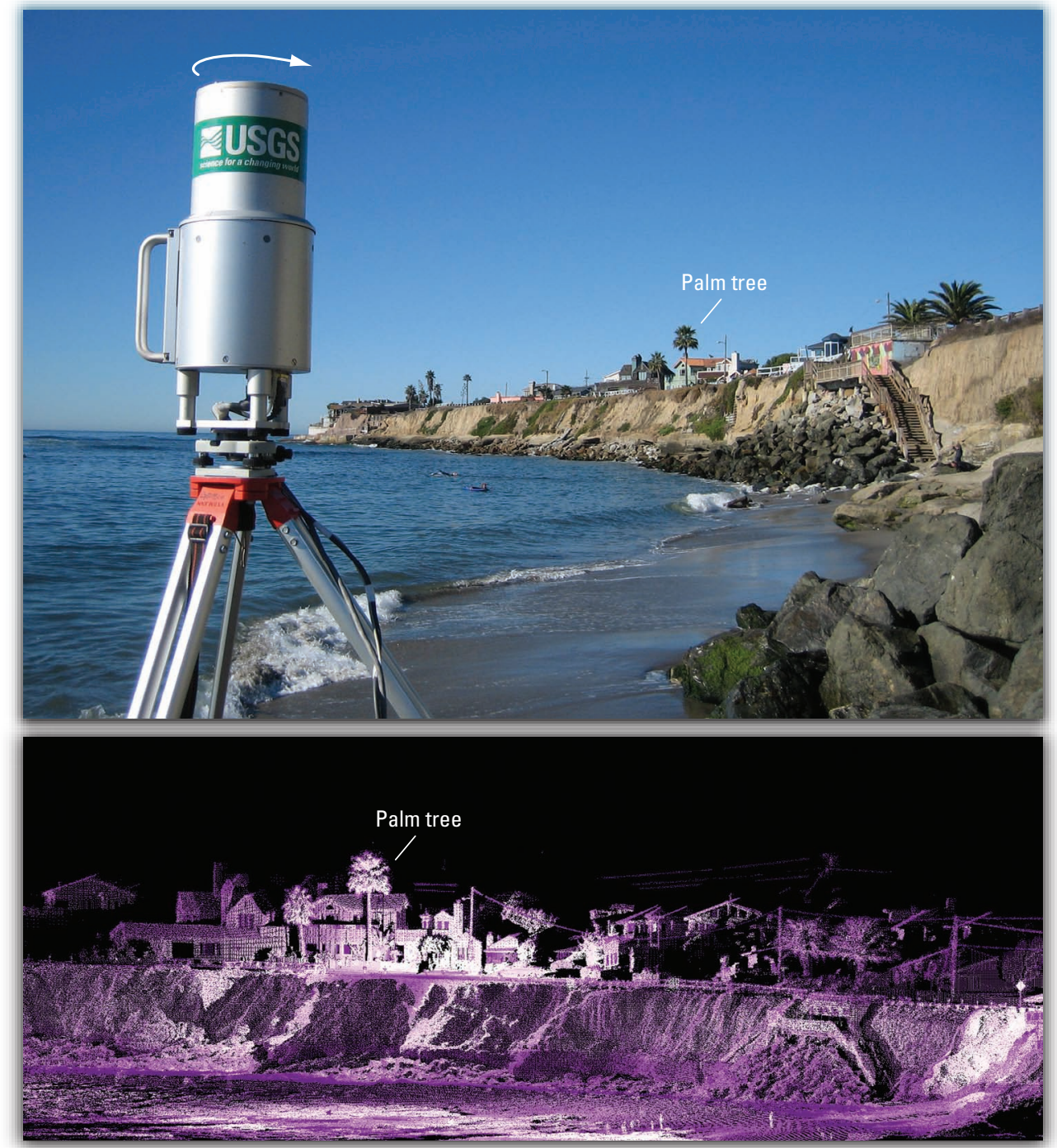

The upper photograph shows a U.S. Geological Survey tripod-mounted lidar scanner positioned to scan the coast at Pleasure Point in Santa Cruz, California. The scanner is fixed with respect to the ground at a location, and a three-dimensional array of points is obtained from a rapidly pulsing laser beam to collect data in vertical lines, while the head of the scanner pans in the horizontal direction. The lower image shows typical raw data ("point cloud") obtained from a lidar scan of the coastline above.

\section{Methodology-Data Collection and Processing}

Terrestrial lidar technology is based on the laser rangefinder systems and electronic distance meters (EDMs) commonly used in surveying, such as those often observed along roadways. Lidar improves upon EDM techniques by being able to rapidly generate, transmit, and measure the returning signal in a highly efficient manner, such that millions of data points are collected in a matter of minutes. With this technology, a laser beam pulses along a constantly changing, but precisely measured, trajectory and is reflected back to the lidar device in a process termed "laser scanning." By timing the round trip of each laser pulse, 

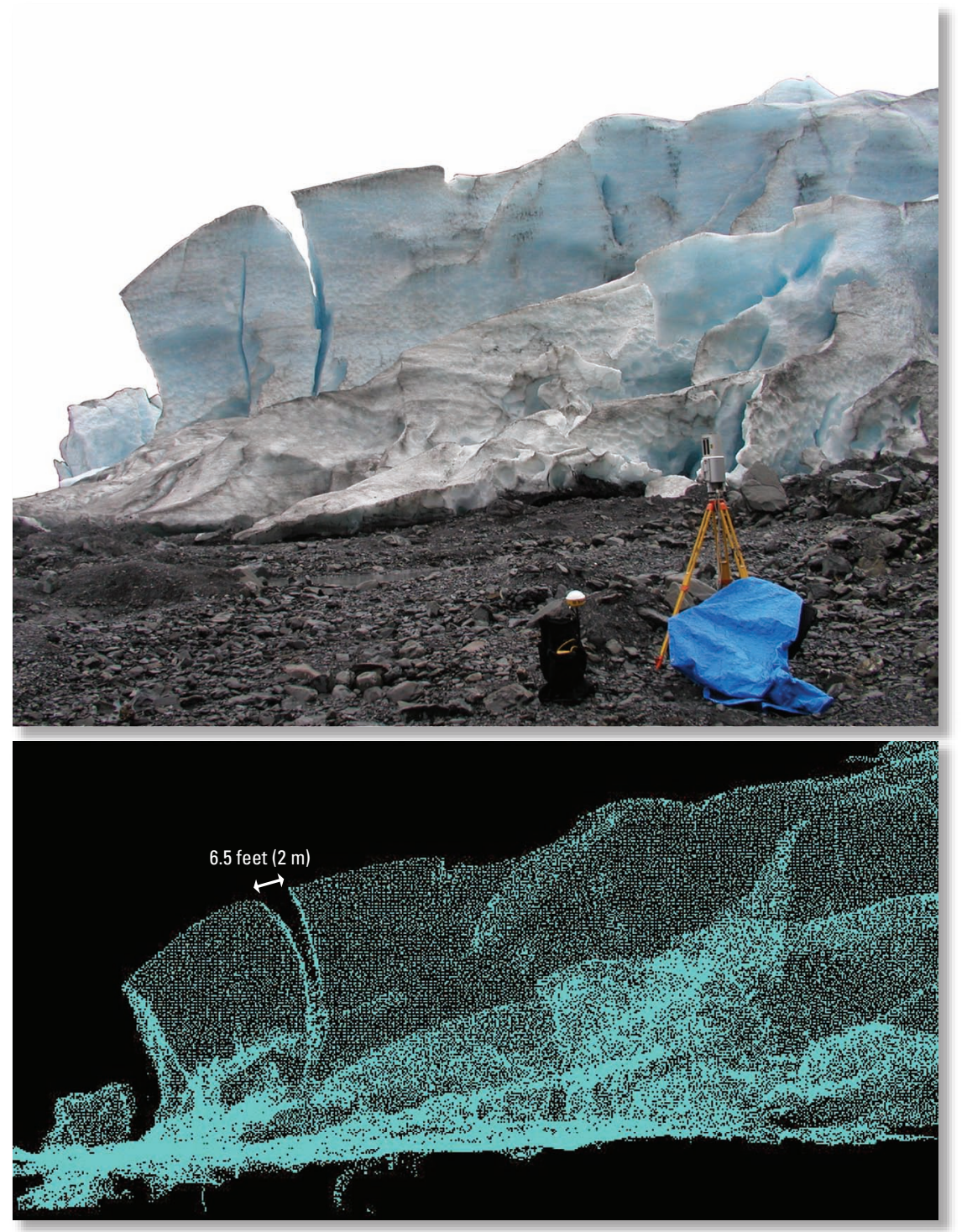

Terrestrial lidar is an effective means of imaging complex, inaccessible terrain. These images show a lidar setup at the toe of Exit Glacier near Seward, Alaska. The large tension cracks visible in the photograph (top) were formed as an overhanging section of ice moved away from the main body of the glacier. Computer-processed lidar data (bottom) from the glacier allow measurement of the crack patterns and dimensions for understanding glacial processes.

the precise range is determined for each scan position, and a series of coordinates are recorded (generally referred to as a "point cloud"). As the laser pulses are reflected back from objects at various distances from the scanner, point measurements are collected that define each object's shape. To gather panoramic data at a given scene, the scanner slowly pans about a fixed base in the horizontal plane, while a rotating mirror reflects the laser at various trajectories in the vertical plane.

The USGS terrestrial lidar system uses a near-infrared, pulsed-laser diode to transmit and receive laser signals. In addition, a true-color sensor included in the lidar system automatically assigns each point a color value on the basis of field lighting conditions. The system is portable and designed for rapid acquisition of high-resolution threedimensional imagery under outdoor conditions. From a fixed station, a single lidar scan can sweep as much as $336^{\circ}$ in the horizontal plane and $80^{\circ}$ in the vertical plane. The laser can sense targets at a range as far as 1,100 feet $(350 \mathrm{~m})$ under the best atmospheric conditions, depending on the reflectivity of the given target. The range accuracy is consistently about half an inch (15 mm).

Data are collected at acquisition rates of approximately 500,000 points per minute, providing the ability to quickly image the topography of extremely complex natural surfaces in detail. The data points are converted to surface models after postprocessing to remove foreign objects (birds, people, vehicles, and such) and filtering to a regularly spaced network, typically with a minimum point separation of 4 to 20 inches (10 to $50 \mathrm{~cm}$ ). The points are then registered either to a local coordinate system, using fixed control points located within the scans, or to a global coordinate system, using a highly accurate differential global positioning system (GPS) or standard survey equipment to fix the location of each scanner setup. After processing of consecutively scanned surfaces of the same area at different times, linear and volumetric changes between the surfaces are measured and analyzed.

\section{Measuring Changes in the Natural Environment-from Alaskan Glaciers to Grand Canyon Sandbars}

One application of terrestrial lidar technology is to measure changes in the natural environment, such as glaciers and river sandbars, both of which have been the focus of recent scientific studies by the USGS Coastal and Marine Geology program. Exit Glacier, near Seward, Alaska, is an example of a glacier that has significantly retreated over the past century. With its easily accessible terminus and high retreat rate, this glacier presents the opportunity to study a landscape in motion and to model the mechanics of glacial retreat. Lidar data collected at this site in July 2004 have shown the large magnitude and spatial distribution of ice tension cracks within the glacier terminus and the complex three-dimensional interactions between the retreating glacier and underlying bedrock landforms.

Understanding sandbar evolution in rivers is another area of study in which terrestrial lidar technology is revolutionizing existing methods of measuring change. In Grand Canyon National Park, USGS scientists are studying how sandbars move through erosion and accretion cycles, depending on the flow rate of the Colorado River. Sandbar surveys performed with standard survey techniques are time consuming and require scientists to walk on the sandbar being studied, a procedure that can sometimes degrade sandbar bedforms, especially near the edges of the sandbar. Aerial lidar surveys require extensive logistics and are relatively expensive, and so they are not a feasible option for monitoring short-term change. Terrestrial 


\section{MONITORING CHANGES OF RIVER SANDBARS}
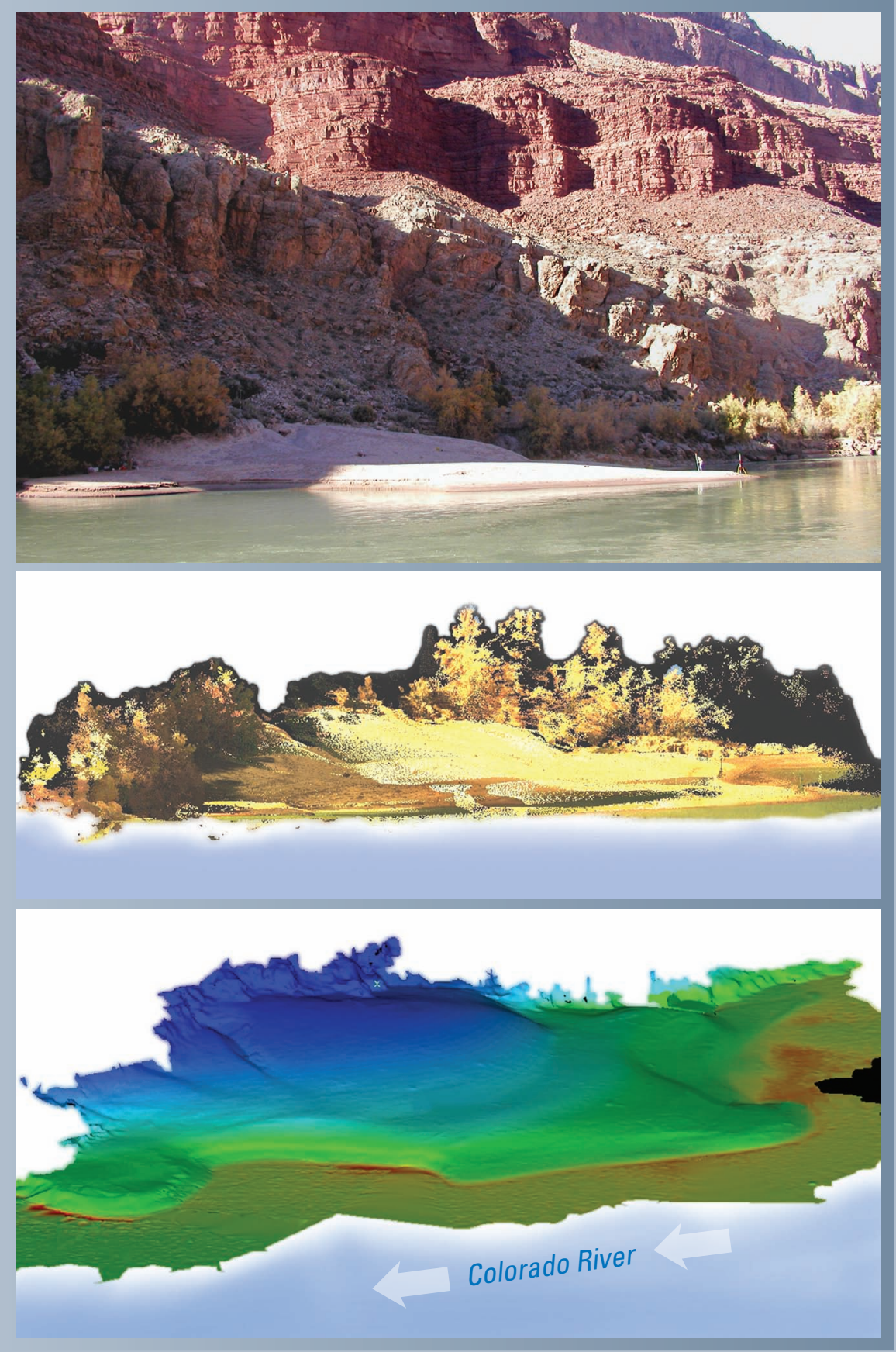

Lidar scanning in Grand Canyon National Park allows a better understanding of the evolution of river sandbars. This series of images shows a photograph (top), the raw lidar point data (middle), and the finished topographic surface model (bottom) of a sandbar along the Colorado River. Repeated surveys of this area will provide vital information on how sandbars accrete and erode in response to fluctuating riverflow and windblown sediment deposition below Glen Canyon Dam.

lidar surveys, however, are easily repeatable and provide a noninvasive technique to quickly obtain the data required by river scientists. During the 2004 Glen Canyon Dam High Flow Test, researchers obtained terrestrial lidar datasets of several areas, including a large fluctuating sandbar, and were successful in demonstrating lidar's usefulness in modeling such complex features.

\section{Documenting the Failure Modes of New Orleans Levees After Hurricane Katrina}

After the failure of the New Orleans levee system during Hurricane Katrina in 2005, one of the ways the USGS responded was to use a terrestrial lidar system to document the failure modes of the compromised levees. An important task with widespread implications, this emergency response collected the only ultra-high-resolution dataset available for characterization of levee deformations immediately after the hurricane.

Here, terrestrial lidar technology was essential for determining the "as failed" condition of the levees for use in forensic investigations. Because the levees were repaired immediately after the city was pumped dry, collecting data in a timely and efficient manner was required. The portability of the USGS lidar system was especially valuable - the scanner was easily mounted to a tripod on the roof of a field vehicle, providing a higher viewing platform and allowing data to be collected over such cultural features as levee floodwalls and into flood-scour trenches on the land side of these same walls. The lidar datasets were initially used by independent teams of researchers investigating the causes of the failures, a report on which was submitted to the U.S. Congress (http://hsgac.senate.gov/_files/ Katrina/Preliminary_Report.pdf). These datasets have also been used by numerous researchers performing geotechnical analyses of the levee failures including the Independent Levee Investigation Team (ILIT), whose final report is available at http://www.ce.berkeley.edu/ new_ orleans/.

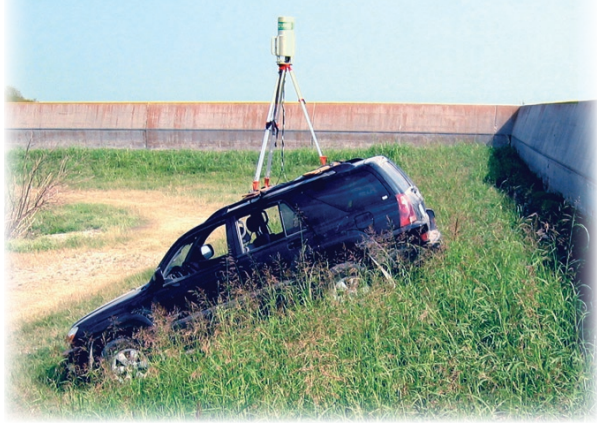

After the passage of Hurricane Katrina in New Orleans in 2005, mobile lidar surveys enabled rapid data reconnaissance of overtopped levee walls. In this photograph, a lidar scanner is mounted to the roof of a vehicle to extend the field of view over floodwalls and into scour trenches formed by water overtopping the walls. Even on the sloping ground shown here, the lidar scanner can easily be leveled on its fixed tripod base to assist in accurate data processing. 


\section{ANALYZING LEVEE FLOODWALL FAILURES}

This cross section (view northward) was developed from lidar datasets of the breached 17th Street Canal in New Orleans after Hurricane Katrina in 2005. Lateral movement of the soil levee and its concrete floodwall, as measured by displacement of a chainlink fence, was approximately 46 feet (14 m). The cross section shows the original position of the concrete floodwall (now destroyed) and the emergency-repair embankment that was constructed after the hurricane to prevent additional flooding and to allow pumping out of the city. Inset photograph shows a lidar scanner set up on the emergency-repair embankment in front of displaced earth blocks.

\section{Analyzing Coastal-Bluff (Seacliff) Landslides from Storm-Induced Erosion}

The Pacific coastline of California, Oregon, and Washington is one of the most dynamic environments in the United States. Along this heavily populated coast, land development and civil infrastructure are commonly threatened by erosion caused by large winter storms. Especially in central California, extensive coastal-bluff erosion and landsliding occur almost every winter. The USGS has been monitoring several stretches of the coast south of San Francisco both to document changing bluff conditions and to analyze and predict landslide events. Efficient use of terrestrial lidar surveys allows steep coastal-bluff areas to be monitored on a monthly or even daily basis, as needed. In contrast to aerial lidar surveys, which are better suited for studies over longer (for example, semiannual or annual) baselines, terrestrial lidar surveys are easily deployed to quickly collect the high-resolution data needed to understand both beach and bluff (seacliff) processes. Along the Pacifica, California, coastline, lidar surveys measured as much as 33 feet $(10 \mathrm{~m})$ of coastal-bluff retreat in less than a single month during the 2002-2003 winter storm season-a telling statistic, considering the close proximity of homes and roads to the ocean. Lidar data have been used to demonstrate a direct link between changing coastal-bluff geometry and the likelihood of bluff failure and land loss at the crest, making continued monitoring important in establishing thresholds for landslide prediction along these bluffs.

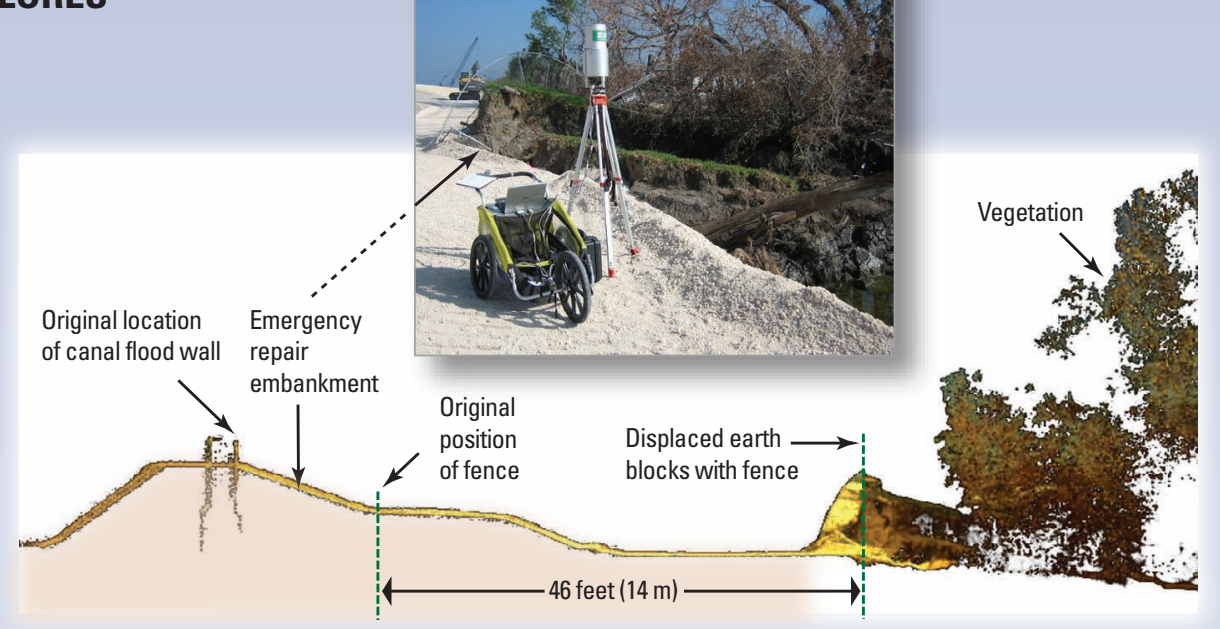

UNDERSTANDING COASTALBLUFF LANDSLIDING

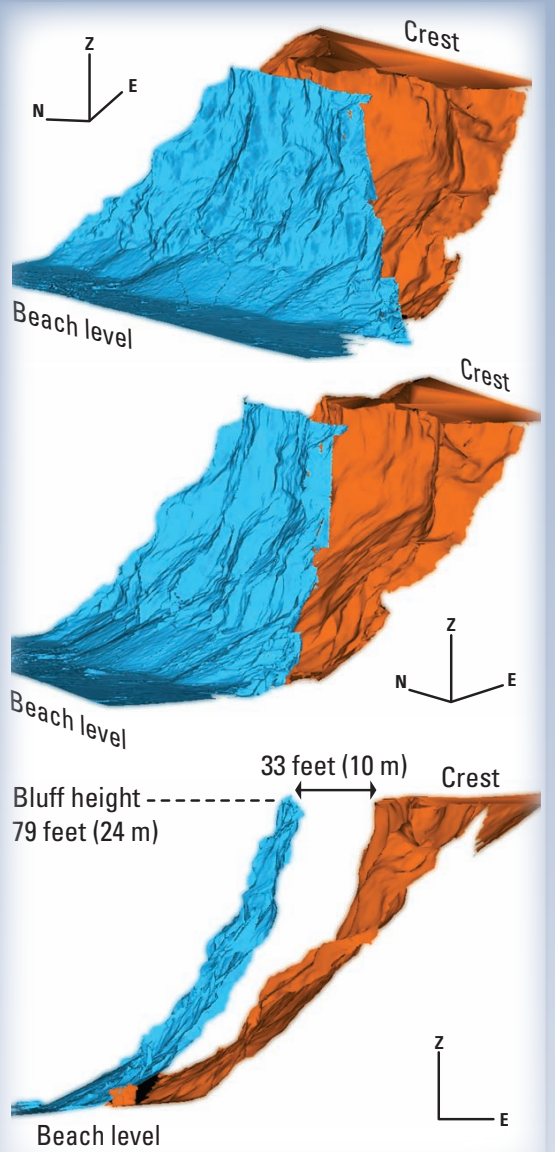

Terrestrial lidar monitoring of seacliff erosion along the Pacific coastline has allowed researchers to analyze the failure modes of coastal-bluff landslides. These three model views, each from a slightly different perspective, show temporally consecutive lidar scans of a coastal-bluff section in Pacifica, California, where 33 feet $(10 \mathrm{~m})$ of crest retreat occurred between October 2002 (blue) and May 2003 (orange). The orientation scale on each image shows $Z$, vertical; $N$, north; and $E$, east.
The Future of Terrestrial Lidar Surveying

With the recent introduction of such a powerful surveying technique as terrestrial lidar, USGS scientists are just beginning to push its limits. Already, new lidar surveys are under way along several stretches of the Pacific coast, while repeat surveys of many sites are performed periodically throughout the year. Among the most recent uses of this technology are lidar-scanning the headwalls of glacial cirques to evaluate rockfall potential and measure erosion, collecting landform data to monitor erosion of archeological sites in the Grand Canyon, and continued application as both a change-detection and a disaster-response tool for learning about our constantly changing world.

The development and use of new surveying techniques, like terrestrial lidar, is only a part of USGS efforts to protect people's lives and property from geologic and environmental hazards in the coastal zones and other areas of the United States.

Brian D. Collins and Robert Kayen

Edited by George A. Havach

Graphic design by Jeanne S. DiLeo

For more information, contact: U.S. Geological Survey Western Coastal and Marine Geology 345 Middlefield Road Menlo Park, CA 94025 650-329-5042

http://walrus.wr.usgs.gov/

This Fact Sheet and any updates to it are available online at

http://pubs.usgs.gov/fs/2006/3111/ 